\title{
The effect of rise time on
}

\section{vibrotactile thresholds*}

\author{
RONALD T. VERRILLO† \\ Laboratory of Sensory Communication \\ Syracuse University, Syracuse, N.Y. 13210
}

Thresholds of detectability were determined for vibration over the thenar eminences of six Ss at frequencies of 25 and $250 \mathrm{~Hz}$ as a function of the rise times of the envelopes of sinusoidal bursts. The results showed no effect over rise times ranging from $16 \mathrm{microsec}$ to $160 \mathrm{msec}$, indicating that for long $(1,000 \mathrm{msec})$ sinusoidal bursts the rise time is not an important parameter in the determination of vibrotactile thresholds.

Displacement rise times of sinusoidal bursts used in vibrotaction experiments varies in different studies and often is not reported at all. This parameter of the stimulus is thought to be important in threshold experiments, since the stimulation of the nerve ending within the Pacinian corpuscle is known to be dependent upon some critical velocity of the mechanical displacement (Lowenstein \& Mendelson, 1965). Working with encapsulated, decapsulated, and an artificial corpuscle, Lowenstein and Mendelson showed that the capsule transmits fast mechanical transients well, but does not transmit slow transients to the center of the corpuscle where the nerve ending is located. Hill (1967) used $10-\mathrm{Hz}$ square waves with variable rise times to show that psychophysically determined thresholds on skin did shift as a function of rise time. Maximum sensitivity was obtained for rise times of $4 \mathrm{msec}$ or less. Thus, in two experiments differing widely in experimental approach and conditions, rise time emerges as an important parameter. The present experiments were performed to determine the effect of rise time using stimuli most frequently encountered in vibrotactile experiments, j.e., the rise time of pulsed bursts of sinusoids of relatively long duration.

APPARATUS AND METHOD

Detailed descriptions of the apparatus and experimental conditions are given in previous publications (Verrillo, 1963, 1968). Thresholds of detectability for vibrotaction were determined for six Ss using a Békésy recording attenuator. The stimulus signal consisted of $25-$ and $250-\mathrm{Hz}$ sinusoids pulsed in a time sequence of

This study was supported by Grant GB-8412 from the National Science Foundation and by Grant NINDB-NB03950 from the National Institutes of Health, U.S. Department of Health. Education and Welfare.

tAddress: Laboratory of Sensory Communication. Srracuse (niversity. 821 Eniversity Avenue. Syracuse. $\therefore . \%, 1.3210$.
$1 \mathrm{sec}$ on with a 1 -sec interstimulus interval. The threshold measurements were made for a randomly presented sequence of rise times at values of 16 microsec and 4.0,8.0,16,30,60, and $160 \mathrm{msec}$.

The rise times were produced by means of a Grayson-Stadler electronic switch (Model 829C), and they were measured directly from the response of a Goodmans (Model 360A) vibrator while it was loaded by a S's hand in the normal testing position. Measurements were made from the output voltage of an Endevco accelerometer (Model 2221) displayed on the screen of an oscilloscope. The accelerometer was mounted directly on the moving element of the vibrator. Rise time was defined as the time in which the signal increased from $10 \%$ to $90 \%$ of its total amplitude. Rise times measured in this manner are approximately $60 \%$ greater than the indications on the electronic switch. The lowest value of rise time (16 microsec) could not be observed directly, so this value was arrived at by increasing the switch marking ("Fast" or 10 microsec) by $60 \%$.

The Ss were located inside a booth that provided insulation against unwanted noise and vibration. Stimulation was perpendicular to the surface of the skin with a contactor size of $2.9 \mathrm{~cm}^{2}$. The contactor protruded through a hole in a rigid surface which supported the forearm and hand of the $\mathrm{S}$. This served to prevent surface waves on the skin from spreading beyond the locus of stimulation. Measurements were made over the thenar eminence of the right hand. Narrow-band random noise was delivered via insert earphones to prevent the Ss from hearing any acoustic output from the vibrator. Thresholds are reported in decibels referred to 1 micron of peak displacement.

RESULTS AND DISCUSSION

The rise-fall times of sinusoidal bursts at 25 and $250 \mathrm{~Hz}$ had no detectable effect on the individual thresholds of the Ss or on the median thresholds taken across Ss. At $25 \mathrm{~Hz}$, the thresholds measured between 13 and $15 \mathrm{~dB}$ for all rise-fall times, and at $250 \mathrm{~Hz}$ the range of thresholds was between -15.5 and $-17 \mathrm{~dB}$. The thresholds obtained are consistent with data reported from previous experiments (Verrillo, 1963, 1966, 1968). There was no observable tendency for the threshold to vary systematically as a function of the rise-fall time.

This is not a contradiction to the findings of Hill (1967) and Lowenstein \& Mendelson (1965), since they used rectangular pulses of short duration. It is important to remember that the frequency-sensitive skin receptors respond mainly to the onset and cessation of square-wave signals. Neural firing ceases during the static portion of the signal. This means that for square waves, the effective stimulus occurs during the rise- and fall-time portions of the signal. In effect, the skin receptors respond to short pulses of velocity at onset and offset, and rise time becomes synonymous with effective duration. For a pulse of $4.0 \mathrm{msec}$ duration, the frequency spectrum is effectively limited to a maximum frequency of $250 \mathrm{~Hz}$. For narrower pulses, the effective bandwidth is wider and includes $250 \mathrm{~Hz}$, which is in the region of maximum sensitivity for the skin. This may explain the flat low-threshold portion of Hill's curve. For rise times longer than $4.0 \mathrm{msec}$, the energy is effectively limited at progressively lower frequencies. The threshold is then determined by frequencies in a region where skin receptors become progressively less sensitive. This is reflected in Hill's data by an increasing threshold as a function of rise time greater than $4.0 \mathrm{msec}$. For bursts of sinusoids, the receptors respond to each cycle of the carrier frequency and energy is summated over the duration of the burst. Thus, the threshold of detectability is governed by the carrier frequency of the stimulus and the burst duration. The results reported here are consistent with this reasoning.

The effect of rise time at values between $16 \mathrm{microsec}$ and $160 \mathrm{msec}$ may be ruled out as an important parameter in the determination of vibrotactile thresholds for sinusoidal bursts of long duration ( $1,000 \mathrm{msec})$. Under these conditions, the threshold appears to be completely determined by the carrier frequency rather than by the rate of growth of the envelope of the signal. The effect of rise time on stimuli of shorter duration should be investigated systematically.

REFERENCES

HILL. J. W. The perception of multiple tactile stimuli. Technical Report 
No. 4823-1. Stanford Electronics Laboratories, Stanford, Calif., 1967.

LOWENSTEIN, W. R., \& MENDELSON, M. Components of receptor adaptation in a Pacinian corpuscle. Journal of Physiology, 1965, 177, 377-397.
VERriLLO. R. T. Effect of contactor drea on the vibrotactile threshold. Journal of the Acoustical Society of America, 1963. 35, 1962-1966.

VERRILLO. R. T. Effect of spatial parameters on the vibrotactile threshold.
Journal of Experimental Psychology. $1966,71,570-575$.

VERRILLO, R. T. A duplex mechanism of mechanoreception. In $D$. $R$. Kenshalo (Ed.). The skin senses. Springfield: Charles C Thomas. 1968.

\section{CURRENT LITERATURE ON HEARING}

BERNSTEIN, I. H. (University of Texas at Arlington, Arlington, Tex. 76010), \& EDELSTEIN, B. A. Effects of some variations in auditory input upon visual choice reaction time. Journal of Experimental Psychology, 1971, 87, 241-247.

CONRAD, R. (Nuffield Hearing and Speech Centre, 330 Grays Inn Road, London, W.C. 1, England). The effect of vocalizing on comprehension in the profoundly deaf. British Journal of Psychology, 1971, 62, 147-150.

EMERSON, P. L. (Cleveland State University, Cleveland, Ohio 44115), CAMUS, E., \& RICHARDS, C. Two-voice music programming system: The PDP-9 as an automatic electronic organ. Behavior Research Methods \& Instrumentation, 1971, 3, 164-166.

FLETCHER, J. F. (University of Western Australia, Nedlands, Western Australia), \& Yates, A. J. The repetition of single speech sounds under delayed auditory feedback . British Journal of Psychology, 1971, 62, 73-79.

FORRESTER, W. E. (State University of New York, Oswego, N.Y. 13126), \& KING, D. J. Effects of semantic and acoustic relatedness on free recall and clustering. Journal of Experimental Psychology, 1971, 88, 16-19.

HER MELIN, B. M. (MR C Developmental Psychology Unit, Gordon Street, London, England), \& O'CONNOR, N. Children's judgements of duration. British Journal of Psychology, 1971, 62, 13-20.

LaBERGE, D. (University of Minnesota, Minneapolis, Minn. 55455 ). Effect of type of catch trial upon generalization gradients of reaction time. Journal of Experimental Psychology, 1971, 87, 225.228.

MADIGAN, S. A. (University of Southern California, Los Angeles, Calif. 90007). Modality and recall order interactions in short-term memory for serial order. Journal of Experimental Psychology, 1971, 87, 294-296.

MALTZMAN, I. (University of California, Los Angeles, Calif. 90024), SMITH, M. J., KANTOR, W., \& MANDELL, M. P. Effects of stress on habituation of the orienting reflex. Journal of Experimental Psychology, 1971, 87, 207-214.

MASSARO, D. W. (University of Wisconsin, Madison, Wis. 53706).
Effect of masking tone duration on preperceptual auditory images. Journal of Experimental Psychology, 1971, 87, 146-148.

McGLAUGHLIN, A. (University of Hull, Hull, England), \& DALE, $H$. C. A. Stimulus similarity and transfer in long-term paired-associate learning. British Journal of Psychology, 1971, 62, 37-40.

PERROTT, D. R. (California State College at Los Angeles, Los Angeles, Calif. 90032), \& FOBES, J. L. Autokinesis as a binaural localization phenomenon: Effects of signal bandwidth. Journal of Experimental Psychology, 1971, 87, 172-175.

RICH, R. (Monash University, Clayton, Victoria, Australia). Constant ratio rule for confusion matrices from short-term memory experiments. British Journal of Psychology, 1971, 62, 27-35.

WARM, J. S. (University of Cincinnati, Cincinnati, Ohio 45221), \& ALLUISI, E. A. Influence of temporal uncertainty and sensory modality of signals on watchkeeping performance. Journal of Experimental Psychology, 1971, 87, 303-308. 